\title{
SOME LIKE IT HOT: MASS EXTINCTION AND THE LATITUDINAL DISTRIBUTION OF MESOZOIC BRACHIOPOD DIVERSITY
}

\author{
WALSH, Joseph A. Department of Geophysical Sciences, University of \\ Chicago, 5734 South Ellis Avenue, Chicago IL 60637, USA
}

Species and genera of living articulate brachiopods are more diverse in temperate than tropical latitudes, a pattern that differs strongly from that shown by most clades. This was not so in the Permian, but the latitudinal distribution of articulates between the Permian and the Recent has not been studied. The first step in understanding how Recent articulates came to be excluded from low latitudes, and therefore the relative importance of competition, escalation, mass extinction, and other forces in determining macroevolutionary patterns, is to constrain more precisely the time at which this exclusion arose.

Low genus diversity at low paleolatitudes is not a direct outcome of the end-Permian extinction. During the Anisian and Ladinian, more genera of all four articulate orders (Strophomenida, Spiriferida, Terebratulida and Rhynchonellida) occurred in low (i.e., $0^{\circ}-20^{\circ}$ ) than middle $\left(21^{\circ}-40^{\circ}\right)$ paleolatitudes. By the Carnian and Norian, articulate faunas were more diverse in middle than low paleolatitudes, and this pattern has prevailed without substantial change to the present day. Exclusion from low paleolatitudes was reinforced by the end-Triassic mass extinction. Brachiopods are not found in low-paleolatitude localities in the Lower Lias, and the partial low-paleolatitude recovery shown by the Middle and Late Jurassic can be attributed to the expansion of a small suite of terebratulide and rhynchonellide clades from middle paleolatitudes, rather than to origination of families or even subfamilies in situ. This pattern of low-paleolatitude exclusion then persisted generally unchanged to the present day.

These results suggest that the failure of post-Paleozoic articulate brachiopods to recapture Paleozoic levels of taxonomic diversity is attributable to events following recovery from the end-Permian mass extinction, rather than to patterns of survivorship from the mass extinction itself, or to the Mesozoic Marine Revolution of the Late Jurassic and Cretaceous. The diversity of taxa within localities mirrors the global trend, suggesting that the pattern is not simply an artifact of preservational bias. 